\title{
Differences in Lower-Body Stiffness Between Levels of Netball Competition
}

\author{
Elizabeth C. Pruyn, ${ }^{1}$ Mark L. Watsford, ${ }^{1}$ and Aron J. Murphy ${ }^{2}$ \\ ${ }^{1}$ Faculty of Health, Sport and Exercise Discipline Group, University of Technology Sydney, Sydney, Australia; and ${ }^{2}$ School of \\ Science and Technology, University of New England, Armidale, Australia
}

\begin{abstract}
Pruyn, EC, Watsford, ML, and Murphy, AJ. Differences in lowerbody stiffness between levels of netball competition. J Strength Cond Res 29(5): 1197-1202, 2015-There are many notable differences in physical and skill attributes between competition levels, especially in team sports. Stiffness is an important mechanical factor to measure when considering athletic performance and injury incidence. Active vertical stiffness $\left(\mathrm{K}_{\mathrm{vert}}\right)$ during hopping and passive stiffness during lying and standing were measured during the preseason period for 46 female netballers $(24.0 \pm 3.7$ years, $72.2 \pm 7.6 \mathrm{~kg}, 175.2 \pm 6.7$ $\mathrm{cm})$. Participants were classified as elite, sub-elite, representative or recreational based on their current level of competition. A 1-way analysis of variance revealed that elite players possessed significantly higher $\mathrm{K}_{\text {vert }}$ than recreational players $(p=$ 0.018). Large effect sizes (ES) suggested that elite players also possessed higher $\mathrm{K}_{\text {vert }}$ than sub-elite $(d=1.11)$ and representative $(d=1.11)$ players. A number of large and moderate ES were also present when comparing the passive stiffness of elite players to their lower-ranked counterparts. The results of this study suggest that elite players possess higher levels of active stiffness when compared with their lower-ranked counterparts. The differences in stiffness levels may contribute to a player's ability to physically perform at an elite level and also provide one explanation into elevated rates of injury at higher levels of competition.
\end{abstract}

KEY WoRDS vertical stiffness, hopping, myometry, court sport

\section{INTRODUCTION}

I $\mathrm{n}$ competitive sports, there are distinct differences in physical and skill attributes between various competition levels. Recently, there have been a number of studies exploring the differences between relevant performance characteristics of players from different levels of competition within various sports. These include reports of

Address correspondence to Elizabeth C. Pruyn, ruyn@uts.edu.au.

29(5)/1197-1202

Journal of Strength and Conditioning Research

(C) 2015 National Strength and Conditioning Association athletes competing at higher levels of competition displaying significantly greater upper- (1) and lower-body strength $(1,16)$, rate of force development (16), jump performance (16), speed (16), and sport-specific skill performance $(14,22)$ than their lower-ranked counterparts. Each of the aforementioned physical indicators requires the effective use of the stretch-shorten cycle (SSC); therefore, this is an important variable to assess when considering athlete selection and physical development.

Stiffness is an important mechanical property of the musculotendinous unit when considering the storage and release of elastic energy in SSC activities. In terms of athletic ability, relatively high levels of stiffness have been related to superior performance of a number of key performance indicators in team-sport athletes, including speed $(3,34)$, acceleration (18), running economy $(7,35)$, rate of force development (39), vertical jump performance $(29,36)$, and strength (39). The execution of these key performance indicators relies on the effective implementation of relatively fast SSC movements. Because athletes competing at higher levels of competition have demonstrated greater performances in many of these abilities that have also been related to relatively high levels of stiffness, it can be postulated that higher caliber players would possess relatively higher levels of stiffness than lower caliber players. This concept is yet to be assessed in the scientific literature.

It is important to compare the stiffness characteristics of various playing levels, as stiffness is not only related to performance of critical physical attributes but also related to injury incidence. Relatively high levels of stiffness have been associated with bony, overuse-type injuries $(17,38)$, and softtissue injuries in the lower body $(8,37)$. In addition, relatively high levels of bilateral asymmetry in stiffness have previously been linked to injury risk $(31,37)$. Two primary concerns of athletes, coaches, and team management are optimal performance and minimization of injury and because stiffness is potentially related to both, it is an important muscle property to investigate in a variety of sports. Further, stiffness is a neuromuscular variable that is reportedly modifiable with appropriate training $(25,35)$.

Netball is a popular court sport in the Commonwealth countries, in particular with women. Typical game movements include short sprints, agility movements, jumping, and 
bounding (23), each of which involves the effective storage and release of elastic energy, and are therefore modulated, in part, by levels of stiffness. Because the high impacts associated with repeated jumping, landing, and stop-start movements, the rate of injury incidence in netball is relatively high $(12,30)$. Netball injuries predominantly occur in the lower limbs and are most commonly soft-tissue injuries $(30,33)$. Of particular concern is the high incidence of severe lower-body soft-tissue injuries such as anterior cruciate ligament rupture and Achilles tendon injury (13) because these injuries often require surgical intervention and lengthy recovery periods.

Previous reports have identified a positive relationship between stiffness and superior performance of relatively fast SSC activities. Because netball typically involves dynamic SSC movements, it is plausible to hypothesize that athletes participating at higher levels of netball competition would possess higher stiffness of the lower body than those competing at lower levels. Further, there is evidence to suggest that a greater number of netball injuries occur at higher levels of competition $(20,21)$. Because relatively high stiffness has also been associated with the most common types of injuries occurring in netball, it may be postulated that the higher levels of lower-body stiffness associated with higher levels of netball competition contribute to the greater incidence of injury.

The aim of this study was to examine for any differences in lower-body stiffness between athletes participating at various levels of netball competition. It was hypothesized that elite players would have higher lower-body stiffness than lower-ranked players.

\section{MeTHODS}

\section{Experimental Approach to the Problem}

Understanding the stiffness characteristics of players competing at different levels of competition in netball is necessary to indicate the consequences of an increase in training load and match demands. Because injuries occur more often at higher levels of competition, highlighting the difference in stiffness levels may provide some insight into this incidence. In a cross-sectional study, stiffness measurements were collected from all participants immediately before the commencement of their respective competitive seasons. Vertical stiffness $\left(\mathrm{K}_{\mathrm{vert}}\right)$ was measured to assess stiffness of the lower body during active motion, whereas the passive stiffness of various lower leg sites was collected in 2 positions using myometry. By measuring both dynamic and passive stiffness, this study provided a holistic and robust analysis of the viscoelastic muscle properties that have previously been related to function and injury risk.

\section{Subjects}

Forty-six female netballers ([mean $\pm S D]$ age, $24.0 \pm 3.7$ years; body mass, $72.2 \pm 7.6 \mathrm{~kg}$; height, $175.2 \pm 6.7 \mathrm{~cm})$ volunteered to participate in the study. No subjects were under 18 years of age. Participants were injury free at the time of testing and had not sustained a lower-body injury during the 3 months before testing. Participants were allocated to groups according to the level of competition at which they were currently competing; elite $(n=9)$, sub-elite $(n=17)$, representative $(n=11)$, and recreational $(n=8)$. As part of their scheduled programs, the elite group completed up to 10 hours of conditioning and on-court training per week. Sub-elite and representative athletes completed up to 2 hours of team training per week, whereas the recreational group did not participate in any formal training. The study was conducted with ethics approval from the Human Research Ethics Committee of the University of Technology Sydney, and had no external financial support. Participants gave their written informed consent before the commencement of the study.

\section{Procedures}

To assess $\mathrm{K}_{\mathrm{vert}}$, participants were required to hop unilaterally on a 1-dimensional force platform (Onsport, Wollongong, Australia) in time to a digital metronome (Seiko, Tokyo, Japan) set at $2.2 \mathrm{~Hz}(9,10,27)$. To prevent any contribution from the upper body, participants kept their hands on their hips, and the test was performed barefoot to eliminate any cushioning effect from footwear. Verbal feedback was given to ensure steady-state hopping occurred. Once this was achieved, 10 seconds of force data was collected at 1,000 $\mathrm{Hz}$. If trials fell outside $\pm 2 \%$ of the prescribed frequency, they were repeated after 1 minute of rest. All participants completed this protocol once on both their right and left legs. $K_{v e r t}$ was calculated as the ratio of peak ground reaction force to the maximum center of mass displacement at the middle of the ground contact phase $(11,27)$. Similar methodology has reports of excellent reliability (27). For each data file, the mean stiffness of 3 consecutive hops was divided by body mass to produce a score relative to individual size. The average of right and left stiffness scores was calculated to determine bilateral mean $\mathrm{K}_{\mathrm{vert}}$ for each participant. Stiffness asymmetry for $\mathrm{K}_{\mathrm{vert}}$ was recorded as a percentage of the value from the leg with the lower stiffness score.

Myometry was used to assess the passive stiffness of 4 sites of the lower body (lateral gastrocnemius [LG], medial gastrocnemius [MG], soleus [SOL], Achilles aponeurosis $[\mathrm{ACH}]$ ) in 2 positions (lying and standing). The participants lay prone on an assessment table with feet hanging off the table at an angle of $90^{\circ}$ and stood in anatomical position. Participants were required to be barefoot with their lower leg exposed. To maintain consistency of measurement between participants and positions, assessment points were drawn on the skin with a marker. Measurements were taken using the latest model of a hand-held myometer, the Myoton-Pro (Myoton AS, Tallinn, Estonia), which was positioned immediately above the skin overlaying the assessment site. A mechanical probe then delivered an impact (duration: 15 
TABLE 1. Participant details for each playing level.*

\begin{tabular}{lcccr}
\hline & Elite $(n=9)$ & Sub-elite $(n=17)$ & Representative $(n=11)$ & Recreational $(n=8)$ \\
\hline Age $(\mathrm{y})$ & $26.1 \pm 4.0$ & $23.5 \pm 4.2$ & $22.7 \pm 1.5$ & $24.5 \pm 3.6$ \\
Height $(\mathrm{cm})$ & $179.8 \pm 5.2 \dagger$ & $176.0 \pm 6.7$ & $173.7 \pm 6.5$ & $170.5 \pm 5.5$ \\
Mass $(\mathrm{kg})$ & $73.8 \pm 5.9$ & $72.9 \pm 9.1$ & $73.0 \pm 5.0$ & $67.8 \pm 8.6$ \\
\hline
\end{tabular}

*Values are expressed as mean $\pm S D$.

$\uparrow$ Significantly different to recreational group $(p=0.018)$.

milliseconds; force: $0.3-0.4 \mathrm{~N}$ ) causing the tissue to briefly deform. An in-built accelerometer, sampling at 3,200 $\mathrm{Hz}$ (5), then measured the damped natural oscillations (2) that occurred. Stiffness was calculated as the ratio of force applied and the muscle deformation (5). Use of the Myoton-Pro has shown high levels of reliability (28), and there have been reports of good construct validity for an earlier model of a myometer (40). Three consecutive measurements were taken at each site in each position, giving a mean stiffness score. For each site and position, the average of right and left legs was taken to form a bilateral mean stiffness score, which was used for further analysis. As with $\mathrm{K}_{\mathrm{ver}}$, stiffness asymmetry was calculated for myometry at each site and position.

\section{Statistical Analyses}

Statistical analyses were performed to compare the stiffness and asymmetry of the 4 playing levels for $\mathrm{K}_{\mathrm{vert}}$ and myometry for each site and position using SPSS Statistics version 21 (IBM, Armonk, NY, USA). Levene's test determined whether homogeneity of variance existed for each set of data, and normality was tested with the Shapiro-Wilk test. The data for all variables were normally distributed and achieved homogeneity of variance. A 1-way analysis of variance with Tukey's post hoc analysis was performed to determine whether there were any significant differences in stiffness between the 4 playing levels. To calculate the magnitude of difference between the groups, measures of effect size (ES) were assessed using Cohen's $d$ :

$$
d=\frac{(\text { mean group } x)-(\text { mean group } y)}{0.5([S D \text { group } x]+[S D \text { group } y])}
$$

The inclusion of ES statistics ensured a robust platform for the analysis of meaningful practical differences between each level of competition. For all statistical procedures, an alpha level of $p \leq 0.05$ was used to establish significance, and ES

TABLE 2. Comparison of stiffness scores between playing levels.*

\begin{tabular}{|c|c|c|c|c|}
\hline & Elite & Sub-elite & Representative & Recreational \\
\hline \multicolumn{5}{|l|}{ Myometer, lying $\left(\mathrm{N} \cdot \mathrm{m}^{-1}\right)$} \\
\hline LG & $350.5 \pm 42.0 \|$ & $331.3 \pm 34.0$ & $339.8 \pm 50.6$ & $333.5 \pm 72.1$ \\
\hline MG & $313.8 \pm 26.0 \| \pi$ & $301.2 \pm 22.3 \#$ & $304.8 \pm 36.7 \#$ & $283.3 \pm 31.1$ \\
\hline SOL & $409.2 \pm 65.3$ & $387.5 \pm 46.9$ & $403.1 \pm 39.6$ & $407.2 \pm 78.6$ \\
\hline $\mathrm{ACH}$ & $423.9 \pm 63.0 \#$ & $403.7 \pm 55.8$ & $407.7 \pm 42.3$ & $388.6 \pm 72.3$ \\
\hline \multicolumn{5}{|c|}{ Myometer, standing $\left(\mathrm{N} \cdot \mathrm{m}^{-1}\right)$} \\
\hline LG & $469.1 \pm 116.8 \#^{\star \star}$ & $451.9 \pm 82.9$ & $412.2 \pm 93.4$ & $420.6 \pm 74.1$ \\
\hline MG & $373.9 \pm 75.9 \#$ & $381.8 \pm 67.5 \pi$ & $389.9 \pm 93.4 \uparrow$ & $326.1 \pm 69.4$ \\
\hline SOL & $639.6 \pm 142.9 \#^{\star *}$ & $596.1 \pm 136.7$ & $576.2 \pm 86.2$ & $560.7 \pm 97.8$ \\
\hline $\mathrm{ACH}$ & $605.4 \pm 168.3 \#^{\star *}$ & $566.4 \pm 113.5$ & $540.0 \pm 78.1$ & $517.7 \pm 113.3$ \\
\hline
\end{tabular}

${ }^{*} \mathrm{~K}_{\text {vert }}=$ vertical stiffness; $\mathrm{LG}=$ lateral gastrocnemius; $\mathrm{MG}=$ medial gastrocnemius; $\mathrm{SOL}=$ soleus; $\mathrm{ACH}=$ Achilles aponeurosis. $\dagger$ Significantly different $(p=0.031)$ and large ES when compared with recreational group.

tLarge ES when compared with sub-elite group.

SLarge ES when compared with representative group.

$\|$ Moderate ES when compared with sub-elite group.

ILarge ES when compared with recreational group.

\#Moderate ES when compared with recreational group; large ES: $d>0.71$; medium ES: $0.5<d<0.7$.

**Moderate ES when compared with representative group. 
TABLE 3. Comparison of stiffness asymmetry (\%) between playing levels.*

\begin{tabular}{lcccc}
\hline & Elite & Sub-elite & Representative & Recreational \\
\hline K $_{\text {vert }}$ & $19.8 \pm 16.3 \dagger$ & $13.9 \pm 10.6 \ddagger$ & $21.6 \pm 19.2 \dagger$ & $10.6 \pm 3.6$ \\
Myometer, lying & $7.7 \pm 4.1$ & $6.2 \pm 4.8$ & $5.7 \pm 5.7$ & $6.7 \pm 3.7$ \\
$\quad$ LG & $6.0 \pm 3.1 \dagger \ddagger$ & $4.6 \pm 4.7 \S$ & $4.2 \pm 2.4 \S$ & $11.0 \pm 8.7$ \\
MG & $10.2 \pm 5.4 \ddagger \|$ & $7.5 \pm 3.7$ & $6.9 \pm 7.6$ & $10.3 \pm 10.4$ \\
SOL & $6.9 \pm 5.4 \uparrow \#$ & $8.8 \pm 6.6 \ddagger$ & $13.2 \pm 6.9 \#$ & $9.6 \pm 5.1$ \\
ACH & $11.7 \pm 8.8$ & $12.3 \pm 8.8$ & $13.5 \pm 17.6$ & $9.6 \pm 6.8$ \\
Myometer, standing & $10.4 \pm 5.7 \ddagger$ & $9.8 \pm 7.9 \ddagger$ & $19.7 \pm 21.2 \#$ & $10.4 \pm 8.8$ \\
LG & $16.5 \pm 18.3 \#$ & $11.5 \pm 11.2$ & $16.7 \pm 15.1 \#$ & $9.1 \pm 7.4$ \\
MG & $12.8 \pm 9.1$ & $11.9 \pm 13.0$ & $17.7 \pm 12.4$ & $15.0 \pm 12.6$ \\
SOL & ACH & & &
\end{tabular}

${ }^{*} \mathrm{~K}_{\text {vert }}=$ vertical stiffness; $\mathrm{LG}=$ lateral gastrocnemius; $\mathrm{MG}=$ medial gastrocnemius; $\mathrm{SOL}=$ soleus; $\mathrm{ACH}=\mathrm{Achilles}$ aponeurosis. † Large ES when compared with recreational group.

\Moderate ES when compared with representative group.

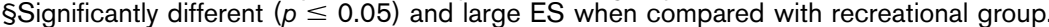

|Moderate ES when compared with sub-elite group.

IL Large ES when compared with representative group.

\#Moderate ES when compared with recreational group; large ES: $d>0.71$; medium ES: $0.5<d<0.7$.

magnitudes were considered to be minimal $(<0.3)$, small $(0.31-$ $0.5)$, moderate $(0.51-0.7)$, or large $(>0.71)(4)$.

\section{Results}

Table 1 depicts the participants' characteristics at each playing level. There were no significant differences between playing levels, with the exception of height between elite and recreational players $(p=0.019)$.

$\mathrm{K}_{\mathrm{vert}}$ scores were significantly higher in elite players when compared with recreational players (Table $2 ; p=0.018$ ). Furthermore, although not achieving statistical significance, there was a large ES when comparing the $\mathrm{K}_{\mathrm{vert}}$ between elite and sub-elite $(d=1.11)$, and elite and representative groups $(d=1.11$; Table 2).

There were no significant differences between groups when comparing the passive stiffness scores measured by myometry under all conditions (Table 2). In the lying position, passive stiffness comparisons between the elite and recreational groups produced a large ES for MG $(d=1.07)$ and a moderate $\mathrm{ES}$ for $\mathrm{ACH}(d=0.52)$. In the standing position, there was a moderate ES for all assessment sites when comparing elite and recreational athletes (LG: $d=0.51$; MG: $d=$ 0.66 ; SOL: $d=0.66$; ACH: $d=0.62$ ). Further trends demonstrated by large and moderate ES are displayed in Table 2 .

When comparing the stiffness asymmetry between groups for $\mathrm{K}_{\mathrm{vert}}$ and myometry, some differences were present (Table 3). When considering the stiffness of the MG in the lying position, recreational athletes had significantly greater levels of asymmetry than sub-elite $(p=0.024)$ and representative athletes $(p=0.028)$. Various differences with large and moderate ES were also present and are displayed in Table 3.

\section{Discussion}

This study measured the active and passive stiffness of 46 netballers competing at various levels of competition. To the best of the authors' knowledge, this is the first study to compare stiffness differences between athletes participating at 4 distinct playing levels in any sport. Therefore, the results of this study will provide pertinent information to athletes, coaches, and medical staff.

Age-related differences in stiffness $(15,26)$ and other mechanical properties of muscles $(6,15,24)$ have been widely documented in the literature. If differences in age were present in this study, results may have been skewed; however, because the results revealed no significant differences in age between each group, they accurately reflect the differences in stiffness between playing level rather than between age groups. Interestingly, there was a significant difference between the height of the elite players and the recreational players. This is not surprising because players with a taller stature are often targeted for development in netball. Nevertheless, because of the methods of assessing stiffness in this study, height is not a confounding factor in the interpretation of stiffness results.

The results demonstrated that the netballers participating at an elite level possessed significantly higher $\mathrm{K}_{\mathrm{vert}}$ during dynamic hopping when compared with their recreational counterparts. Furthermore, there was a large ES when comparing the $\mathrm{K}_{\mathrm{vert}}$ of the elite group to the sub-elite and representative groups. These results are in congruence with the hypothesis and have numerous implications for athlete monitoring and training management. When considering stiffness asymmetry for all variables, no overall trends were 
noticeable when comparing the levels of competition. Although 2 significant relationships and a number of moderate to large ES were present, these did not present consistent outcomes, thus implying that asymmetry is not a factor to consider when discriminating between playing levels. Previous studies have reported that athletes participating at higher levels of competition possess greater strength, rate of force development, speed, and jump performance (16). These performance indicators have also been related to elevated levels of stiffness $(3,4,27,31,34,37)$ and provide an explanation for the significant difference in active stiffness between elite players and lower caliber players presented in this study. Given the established relationship between stiffness and performance of dynamic tasks, the results of this study indicate that lower-body stiffness may be a useful indicator during screening or talent identification. Further investigation into this line of enquiry is essential.

It is also plausible that elite athletes displayed relatively high levels of stiffness because of their greater weekly training demands. Strength training interventions have been reported to increase stiffness over a period of time (35). With the significant difference in $\mathrm{K}_{\mathrm{vert}}$ evident between the elite and recreational groups, it must be noted that these 2 groups also possess the greatest difference in weekly training demands. Specifically, the recreational group completed no formal training, which is in distinct contrast to the elite group who participated in up to 10 hours of training each week. This training consists of a variety of on-court running and agility drills along with several strength sessions. The sub-elite and representative groups also participated in regular formal training, albeit considerably less than the elite group. Accordingly, differences in $\mathrm{K}_{\mathrm{vert}}$ between these groups and the elite group, as demonstrated by the very large ES, may also be attributed to lower weekly training loads.

Interestingly, the analysis revealed no significant differences between any groups when considering the passive stiffness measured by myometry (Table 2). Although no significant differences were found, the elite group recorded the highest stiffness in 7 of the 8 conditions for testing passive stiffness with myometry. Although not statistically significant, the presence of a number of differences with moderate to large ES, when comparing the elite group to lower-ranked groups, supports the hypothesis of this study and the active stiffness results.

The results of this study suggest that stiffness differences between athletes of different playing levels are more evident during dynamic assessment than when tested under passive conditions. This becomes pertinent when considering the application of these results, as the conditions for assessing $\mathrm{K}_{\mathrm{vert}}$ more closely represent movements performed in a netball game than the passive conditions used for myometry. Netball primarily involves dynamic movements such as running, jumping, and striding, and hopping is a simple bouncing gait (19) that closely represents the demands of high levels sports (32). Thus, the active stiffness levels measured during hopping, as opposed to passive stiffness measurements or asymmetry indexes, may be more indicative of the stress placed on the athlete that could potentially lead to injury, and the athlete's ability to produce power in terms of performance variables. Therefore, if coaches and conditioning staff wish to monitor the stiffness of their athletes, they may wish only to assess stiffness during active motion, as this seems to be most relevant to training and game situations. Because this study has identified a relationship between higher playing level and greater stiffness, it is important that athletes, coaches conditioning staff are informed of the optimal level of stiffness to enhance performance while minimizing the risk of injury. Further research into the stiffness-injury relationship is required to define an optimal stiffness zone.

\section{Practical Applications}

The results from this study suggest that elite netballers possess significantly higher lower-body stiffness during active motion, and a tendency for higher lower-body stiffness under passive conditions. Because injury rates among netballers are greater in higher levels of competition, the difference in stiffness levels may provide one explanation into this occurrence. Stiffness testing is relatively simple to administer in a time-efficient manner and could be used as a tool to monitor injury risk and physical performance in netballers and other court-sport athletes.

\section{REFERENCES}

1. Argus, CK, Gill, ND, and Keogh, JW. Characterization of the differences in strength and power between different levels of competition in rugby union athletes. J Strength Cond Res 26: 26982704, 2012.

2. Bizzini, $\mathrm{M}$ and Mannion, AF. Reliability of a new, hand-held device for assessing skeletal muscle stiffness. Clin Biomech (Bristol, Avon) 18: 459-461, 2003.

3. Bret, C, Rahmani, A, Dufour, AB, Messonnier, L, and Lacour, JR. Leg strength and stiffness as ability factors in $100 \mathrm{~m}$ sprint running. J Sports Med Phys Fitness 42: 274-281, 2002.

4. Cohen, J. Statistical Power Analysis for the Behavioural Sciences. Hillsdale, NJ: Lawrence Earlbaum Associates, 1988.

5. Ditroilo, M, Hunter, AM, Haslam, S, and De Vito, G. The effectiveness of two novel techniques in establishing the mechanical and contractile responses of biceps femoris. Physiol Meas 32: 13151326, 2011.

6. Doherty, TJ. The influence of aging and sex on skeletal muscle mass and strength. Curr Opin Clin Nutr Metab Care 4: 503-508, 2001.

7. Dutto, DJ and Smith, GA. Changes in spring-mass characteristics during treadmill running to exhaustion. Med Sci Sports Exerc 34: 1324-1331, 2002.

8. Ekstrand, J and Gillquist, J. The avoidability of soccer injuries. Int $J$ Sports Med 4: 124-128, 1983.

9. Farley, CT, Blickhan, R, Saito, J, and Taylor, CR. Hopping frequency in humans: A test of how springs set stride frequency in bouncing gaits. J Appl Physiol (1985) 71: 2127-2132, 1991.

10. Farley, CT and Morgenroth, DC. Leg stiffness primarily depends on ankle stiffness during human hopping. J Biomech 32: 267-273, 1999. 
11. Ferris, DP and Farley, CT. Interaction of leg stiffness and surfaces stiffness during human hopping. J Appl Physiol (1985) 82: 15-22, 1997.

12. Finch, C, daCosta, A, Stevenson, M, Hamer, P, and Elliott, BC. Sports injury experiences from the Western Australian sports injury cohort. Aust N Z J Public Health 26: 462-467, 2002.

13. Flood, L and Harrison, JE. Epidemiology of basketball and netball injuries that resulted in hospital admission in Australia, 2000-2004. Med J Aust 190: 87-90, 2009.

14. Gabbett, T, Kelly, J, and Pezet, T. Relationship between physical fitness and playing ability in rugby league players. $J$ Strength Cond Res 21: 1126-1133, 2007.

15. Gajdosik, RL, Vander Linden, DW, and Williams, AK. Influence of age on length and passive elastic stiffness characteristics of the calf muscle-tendon unit of women. Phys Ther 79: 827-838, 1999.

16. Gissis, I, Papadopoulos, C, Kalapotharakos, VI, Sotiropoulos, A, Komsis, G, and Manolopoulos, E. Strength and speed characteristics of elite, subelite, and recreational young soccer players. Res Sports Med 14: 205-214, 2006.

17. Grimston, SK, Ensberg, JR, Kloiber, R, and Hanley, DA. Bone mass, external loads, and stress fractures in female runners. Int J Sport Biomech 7: 293-302, 1991.

18. Hobara, $\mathrm{H}$, Inoue, $\mathrm{K}$, Gomi, $\mathrm{K}$, Sakamoto, $\mathrm{M}$, Muraoka, T, Iso, $\mathrm{S}$, and Kanosue, $\mathrm{K}$. Continuous change in spring-mass characteristics during a $400 \mathrm{~m}$ sprint. J Sci Med Sport 13: 256-261, 2010.

19. Hobara, H, Kanosue, K, and Suzuki, S. Changes in muscle activity with increase in leg stiffness during hopping. Neurosci Lett 418: 55-59, 2007.

20. Hopper, DM. A survery of netball injuries and conditions related to these injuries. Aust J Physiother 32: 231-239, 1986.

21. Hopper, DM, Elliott, BC, and Lalor, J. A descriptive epidemiology of netball injuries during competition: A five year study. Br J Sports Med 29: 223-228, 1995.

22. Johnston, RJ, Watsford, ML, Pine, MJ, Spurrs, RW, Murphy, A, and Pruyn, EC. Movement demands and match performance in professional Australian football. Int J Sports Med 33: 89-93, 2012.

23. King, M and Duffield, R. The effects of recovery interventions on consecutive days of intermittent sprint exercise. J Strength Cond Res 23: 1795-1802, 2009.

24. Kirkendall, DT and Garrett, WE Jr. The effects of aging and training on skeletal muscle. Am J Sports Med 26: 598-602, 1998.

25. Kubo, K, Morimoto, M, Komuro, T, Yata, H, Tsunoda, N, Kanehisa, H, and Fukunaga, T. Effects of plyometric and weight training on muscle-tendon complex and jump performance. Med Sci Sports Exerc 39: 1801-1810, 2007.
26. Lambertz, D, Mora, I, Grosset, JF, and Perot, C. Evaluation of musculotendinous stiffness in prepubertal children and adults, taking into account muscle activity. J Appl Physiol (1985) 95: 64-72, 2003.

27. McLachlan, KA, Murphy, AJ, Watsford, ML, and Rees, S. The interday reliability of leg and ankle musculotendinous stiffness measures. J Appl Biomech 22: 296-304, 2006.

28. Mullix, J, Warner, M, and Stokes, M. Testing muscle tone and mechanical properties of rectus femoris and biceps femoris using a novel hand held MyotonPRO device: relative ratios and reliability. Working Pap Health Sci 1: 1-8, 2013.

29. Murphy, AJ, Watsford, ML, Coutts, AJ, and Pine, MJ. Reliability of a test of musculotendinous stiffness for the triceps-surae. Phys Ther Sport 4: 175-181, 2003.

30. Otago, $\mathrm{L}$ and Peake, J. The role of insurance data in setting priorities for netball injury prevention strategies. J Sci Med Sport 10: 105-109, 2007.

31. Pruyn, EC, Watsford, ML, Murphy, AJ, Pine, MJ, Spurrs, RW, Cameron, ML, and Johnston, RJ. Relationship between leg stiffness and lower body injuries in professional Australian football. $J$ Sports Sci 30: 71-78, 2012.

32. Rudolph, KS, Axe, MJ, and Snyder-Mackler, L. Dynamic stability after ACL injury: who can hop? Knee Surg Sports Traumatol Arthrosc 8: 262-269, 2000.

33. Saunders, N, Otago, L, Romiti, M, Donaldson, A, White, PD, and Finch, C. Coaches' perspectives on implementing an evidenceinformed injury prevention programme in junior community netball. Br J Sports Med 44: 1128-1132, 2010.

34. Seyfarth, A, Geyer, H, Gunther, M, and Blickhan, R. A movement criterion for running. J Biomech 35: 649-655, 2002.

35. Spurrs, RW, Murphy, AJ, and Watsford, ML. The effect of plyometric training on distance running performance. Eur J Appl Physiol 89: 1-7, 2003.

36. Walshe, AD and Wilson, GJ. The influence of musculotendinous stiffness on drop jump performance. Can J Appl Physiol 22: 117-132, 1997.

37. Watsford, ML, Murphy, AJ, McLachlan, KA, Bryant, AL, Cameron, ML, Crossley, KM, and Makdissi, M. A prospective study of the relationship between lower body stiffness and hamstring injury in professional Australian Rules footballers. Am J Sports Med 38: 2058-2064, 2010.

38. Williams, DS III, Davis, IM, Scholz, JP, Hamill, J, and Buchanan, TS, High-arched runners exhibit increased leg stiffness compared to low-arched runners. Gait Posture 19: 263-269, 2004.

39. Wilson, GJ, Murphy, AJ, and Pryor, JF. Musculotendinous stiffness: Its relationship to eccentric, isometric, and concentric performance. J Appl Physiol (1985) 76: 2714-2719, 1994.

40. Zinder, SM and Padua, DA. Reliability, validity, and precision of a handheld myometer for assessing in vivo muscle stiffness. J Sport Rehabil Technical Report 1, 2011. 